Int. J. Odontostomat., 7(2):193-198, 2013.

\title{
Antimicrobial Susceptibility to ß-lactams and Metronidazole of Microorganisms Isolated from Chronic and Aggressive Periodontitis
}

\author{
Susceptibilidad Antimicrobiana a ß-lactámicos y Metronidazol de \\ Microorganismos Aislados de Periodontitis Crónica y Agresiva
}

Elerson Gaetti-Jardim Júnior ${ }^{*}$ Christiane Marie Schweitzer*

GAETTI-JARDIM JÚNIOR, E. \& SCHWEITZER, C. M. Antimicrobial susceptibility to ß-lactams and metronidazole of microorganisms isolated from chronic and aggressive periodontitis. Int. J. Odontostomat., 7(2):193-198, 2013.

\begin{abstract}
The objective of this study was to evaluate the microbial susceptibility to ß-lactams and metronidazole, and evaluate the production of ß-lactamases by microorganisms isolated from patients with chronic or aggressive periodontitis. The samples were obtained from 50 patients with periodontitis and microorganisms were isolated onto selective and nonselective culture media, identified by biochemical methods and tested for susceptibility to antimicrobial agents (amoxicillin, amoxicillin/clavulanate, cefoxitin, imipenem, metronidazole, penicillin $\mathrm{G}$ ). The isolates were resistant to at least $1 \mathrm{mg} / \mathrm{ml}$ of any drug tested were evaluated to verify the production of ß-lactamases by the method of double layer (or biological) and chromogenic cephalosporin using nitrocefin. The results evidenced resistance to amoxicillin and penicillin $\mathrm{G}$, while the susceptibility to association amoxicillin/clavulanate, imipenem and cefoxitin was widely disseminated among the organisms. Resistance to these drugs showed a clear correlation with the production of ß-lactamase in the majority of microbial groups.
\end{abstract}

KEYWORDS: periodontitis, antimicrobials, ß-lactams, bacteria, metronidazole.

\section{INTRODUCTION}

Periodontal diseases represent serious health problems and affect all ethnic groups, regardless gender and socio-economic conditions of the population. They result from the loss of equilibrium between the immune response and virulence factors of the resident microbiota. The control of the oral biofilm is a prerequisite to the health maintenance in the periodontium (Eick et al., 2011). In general, antimicrobial drugs are not indicated as monotherapy for patients with periodontitis, but some aggressive forms of periodontitis may benefit with adjunctive use of systemic antimicrobials (Ahuja et al., 2012).

Several microorganisms have been implicated as pathogens in periodontitis, such as Porphyromonas gingivalis, Prevotella intermedia, P. nigrescens, Tannerella forsythia, spirochetes, Aggregatibacter actinomycetemcomitans and Fusobacterium nucleatum, frequently associated with other Gram- positive and Gram-negative bacteria (López et al., 2011).

Antimicrobials and antibiotics used during treatment of patients unable to maintain oral hygiene, mentally or physically handicapped, suffering from dental and/or surgical trauma, and with refractory, aggressive or advanced periodontitis have been prescribed, but most of these compounds have several side effects. Moreover, the widespread use of antimicrobial agents against oral anaerobes has been associated with a significant increase of the antimicrobial resistance, particularly against ß-lactams (Senhorinho et al., 2012). In addition, most of microorganisms recovered from periodontal sites are strict anaerobes and culture and susceptibility tests of anaerobes are not frequently performed in Brazil, what constitutes a serious problem since clinicians have to choose antimicrobials just using international literature.

\footnotetext{
* Department of Pathology and Clinical Propaedeutics. School of Dentistry of Araçatuba, UNESP-Univ Estadual Paulista, Araçatuba, SP, Brazil " Department of Mathematics, Faculty of Engineering of Ilha Solteira, UNESP-Univ Estadual Paulista, Ilha Solteira, SP, Brazil,

Grants: Fundação de Amparo à Pesquisa do Estado de São Paulo, FAPESP. Process number: 2007/51016-3.
} 
Thus, the aim of this study was to evaluate the susceptibility of microorganisms isolated from chronic and aggressive periodontitis to $\beta$-lactams and metronidazole, and evaluate the production of $B$ lactamases.

\section{MATERIAL AND METHOD}

Patients. This study was approved by the Ethics Committee in Research of the School of Dentistry of Araçatuba. The population of this study consisted of 50 patients with clinical and radiographic characteristics of chronic periodontitis, seen at the School of Dentistry of Araçatuba and private clinics for initial trial for treatment. Patient ages ranged from 26 to 59 years (mean 43.3). Additionally, 8 patients with clinical and radiographic features of aggressive periodontitis, aged from 4.5 to 13 years were included. Medical data revealed that all patients were in good general health. The diagnostic and evaluation of the periodontal status of the patients were carried out by specialists in periodontology and pediatrics.

During the first visit, written informed consent was obtained from each patient or their responsible before enrolment in the study. Patients who had received antibiotics 6 months before the initial clinical trial were excluded. The clinical samples were collected from the 3 deepest non-contiguous periodontal sites (probing depth $\geq 5 \mathrm{~mm}$ ) presenting clinical characteristics of inflammation and loss of attachment. Sample collection was performed by mean of sterile paper points, which were introduced into periodontal pockets and remained there for $30 \mathrm{~s}$. After this procedure, the paper points were pooled and transferred to transport medium VMGA III (Gaetti-Jardim et al., 2012).

Microbial isolation and identification. In the laboratory, aliquots of VMGA III were submitted to serial 10 fold dilutions in VMG I and were plated on fastidious anaerobic agar (FAA) supplemented with yeast extract $(0.5 \%)$, hemin $(1 \mathrm{mg} / \mathrm{mL})$, menadione $(5$ $\mathrm{mg} / \mathrm{mL}$ ) and $5 \%$ horse blood, tryptic soy serum bacitracin vancomycin agar (TSBVA), and incubated in anaerobiosis $\left(90 \% \mathrm{~N} 2+10 \% \mathrm{CO}_{2}\right)$, at $37^{\circ} \mathrm{C}$, for 14 and 3 days, respectively. Pure cultures were obtained and the isolates were subjected to microbial speciation. Initially, the isolates were subjected to Gram staining, evaluation colony morphology on blood agar plates, identification by biochemical tests and amplification of DNA by PCR (Gaetti-Jardim et al.).
A total of 187 isolates of strict and facultative anaerobic bacteria were submitted to the susceptibility tests. Susceptibility to antimicrobial agents was evaluated on 21 isolates of Aggregatibacter actinomycetemcomitans, 11 isolates of Bacteroides $s p ., 13$ isolates of Eubacterium sp., 3 isolates of $E$. lentum, 4 isolates of Fusobacterium sp., 33 isolates of $F$. nucleatum, 5 F. periodonticum, 12 Parvimonas micra, 9 Peptostreptococcus sp., 4 isolates of $P$. anaerobius, 10 Porphyromonas sp., 23 Porphyromonas gingivalis, 5 Prevotella sp., 16 P. intermedia, 7 P. nigrescens, and 11 isolates of Veillonella $s p$.

Antimicrobial susceptibility tests. The minimal inhibitory concentrations were determined by agar dilution method using Wilkins-Chalgren agar supplemented with horse blood, hemin $(1 \mathrm{mg} / \mathrm{mL})$, and menadione $(5 \mathrm{mg} / \mathrm{mL})$. The bacterial inoculum was standardized in 105 cells/spot and transferred to the Petri plates containing the antimicrobials and the control plates (without drugs), using a Steer's replicator (Cefar Ltda, São Paulo, Brazil). The minimum inhibitory concentration (MIC) was defined as the smallest concentration of the drug that completely inhibited the bacterial growth. The following antimicrobial drugs were tested: amoxicillin (Bayer S.A., São Paulo, Brazil), amoxicillin/ clavulanate (Smithkline Beecham Brasil Ltda, São Paulo, Brazil), cefoxitin (Merck Sharp \& Dohme, São Paulo, Brazil), imipenem (Merck Sharp \& Dohme, São Paulo, Brazil), benzylpenicillin (Fontoura-Wyeth S.A., São Paulo, Brazil) and metronidazole (Laboratórios Pfizer Ltda, Guarulhos, Brazil). The breakpoints used for interpretation were those recommended by the Clinical and Laboratory Standards Institute (2007). The test and control dishes were incubated anaerobically $(90 \% \mathrm{~N} 2+10 \% \mathrm{CO} 2)$ at $37^{\circ} \mathrm{C}$, for 48 hours.

F. nucleatum ATCC 10953, F. nucleatum ATCC 25586, E. lentum ATCC 43055, B. fragilis ATCC 23745, E. coli ATCC 25922, S. aureus ATCC 29213 , $P$. aeruginosa ATCC 27853, and E. faecalis ATCC 29212 were used as reference strains for quality control in the susceptibility tests.

Detection of ß-lactamases. All the microorganisms able to resistant to at least $1,0 \mathrm{mg} / \mathrm{mL}$ of the tested blactms were submitted to assays to evaluate the production of ß-lactamases, using biological and chromogenic cephalosporin methods (Gaetti-Jardim et al., 2007). The tested strains included 9 Prevotella 
spp., 2 Peptostreptococcus spp., 12 fusobacteria, and 2 Bacteroides sp. A chromogenic cephalosporin ßlactamase assay using Cefinase disks was performed according to the manufacturer's instructions.

In the biological method, $20 \mu \mathrm{L}$ of cultures of the resistant isolate were plated on the surface of Wilkins-Chalgren agar, containing $1,0 \mu \mathrm{g} / \mathrm{mL}$ of the tested ß-lactam (benzylpenicillin or cefoxitin). These plates were then incubated anaerobically at $37^{\circ} \mathrm{C}$ for 48-72 h. After incubation, the cultures were exposed to chloroform fumes for $20 \mathrm{~min}$ and then covered with $3 \mathrm{~mL}$ of semi-solid brain heart infusion $(\mathrm{BHI})$ agar previously inoculated with 106 cells of Streptococcus pyogenes FOA-94F14, sensitive to all tested ßlactams in a concentration of $\leq 0.06 \mathrm{mg} / \mathrm{mL}$. The Petri dishes were then incubated under aerobiosis for 24 $h$ at $37^{\circ} \mathrm{C}$. After incubation, the presence of this halo of growth was indicative of the degradation of the Blactam. Bacteroides fragilis ATCC 43858 was used as the positive control of $ß$-lactamase production.

\section{RESULTS}

It was not verified any difference in the susceptibility patterns of the isolates recovered from chronic or aggressive periodontitis and the results are presented regardless the source of the clinical samples, in Tables I and II. All strains tested were susceptible to amoxicillin/clavulanate and imipenem, but variable levels of resistance to amoxicillin, benzylpenicillin, and cefoxitin were detected. Resistance to ß-lactams was frequently detected in Gram-negative strict anaerobes, particularly in the genera Fusobacterium, Prevotella and Bacteroides, although some anaerobic cocci also evidenced resistance to these drugs. Resistance to metronidazole was observed in $A$. actinomycetemcomitans (9.5\%); in addition, $19 \%$ of A. actinomycetemcomitans and $8 \%$ of Peptostreptococcus spp. presented intermediate susceptibility to this antimicrobial agent.

Out of 25 bacterial isolates resistant or presenting intermediate susceptibility to to ß-lactams, $20(80 \%)$ were $ß$-lactamase producers $(10.7 \%$ of the isolated bacteria). The production of these hydrolytic enzymes seems to be the major mechanism of resistance to ß-lactams, excluding Bacteroides sp. and peptostreptococci, where ß-lactamases were not detected (Table II).

\section{DISCUSSION}

The effectiveness of the antimicrobials in the treatment of mixed anaerobic infections of the head and neck is undermined by empirical selection of drugs and the problem of self-medication. In addition, microorganisms producing ß-lactamases are frequently detected in dental biofilm from childhood to adulthood particularly in infectious processes (Fosse et al., 2002; Kuriyama et al., 2002).

The strict anaerobes play a major role in the pathogenesis of chronic or aggressive periodontitis and the systemic use of antimicrobial agents may improve the treatment of such infections when associated to local procedures and modification of oral hygiene standards. Moreover, periodontitis is a reservoir of opportunistic pathogens and their eradication depends on use of antimicrobials, particularly ß-lactams (Ahuja et al.), while metronidazole is the frequently used in the therapy of anaerobic mixed infections, specially due to its action on Gram-negative anaerobes associated with oral infections, and its association with amoxicillin has been evaluated in the treatment of aggressive periodontitis (Casarin et al., 2012).

Most studies that deal with the emergence of antimicrobial resistance of oral bacteria have been done in the developed countries and little information is available from south hemisphere (Gaetti-Jardim Júnior et al., 2007). In addition, antimicrobial resistance has expanded considerably, which has rendered traditional prescription habits critical in the absence of laboratorial tests (Baumgartner \& Xia, 2003). This fact is further aggravated when one considers the relevance of the phenomenon of self-medication, which limits the efficacy of treatment and can make prescribing a difficult task, as it modifies the local patterns of susceptibility to drugs.

The resistance to amoxicillin and benzylpenicillin was similar to previously reported in the literature from developing countries (Brescó-Salinas et al., 2006; Gaetti-Jardim Júnior et al., 2007) and evidenced that most of resistant isolates belonged to a peculiar group of Gram Clinical and Laboratory Standards Institute Clinical -negative strict anaerobes, as also reported to bacteria isolated from endodontic infections (GaettiJardim Júnior et al., 2007). The bacteria that accounted for the significantly increased proportion of resistance to amoxicillin and penicillin $\mathrm{G}$ in clinical samples were Gram-negative rods, susceptible to metronidazole. The 
Table I. Susceptibility to antimicrobials of 187 clinical isolates recovered from chronic and aggressive periodontitis.

\begin{tabular}{|c|c|c|c|c|c|c|}
\hline \multirow{2}{*}{ Isolates $(\mathrm{N})$} & \multicolumn{3}{|c|}{$\%$} & \multicolumn{3}{|c|}{$\mathrm{MIC}(\mu \mathrm{g} / \mathrm{mL})$} \\
\hline & $S$ & 1 & $\mathrm{R}$ & range & $\mathrm{MIC}_{50}$ & $\mathrm{MIC}_{90}$ \\
\hline \multicolumn{7}{|l|}{ A. actinomycetemcomitans (21) } \\
\hline amoxicillin & 100 & 0.0 & 0.0 & $\leq 0.006-4$ & 0.25 & 4 \\
\hline amoxicillin/clavulanate & 100 & 0.0 & 0.0 & $\leq 0.006-1$ & 0.25 & 1 \\
\hline benzylpenicillin & 100 & 0.0 & 0.0 & $\leq 0.006-4$ & 0.25 & 4 \\
\hline cefoxitin & 100 & 0.0 & 0.0 & $\leq 0.006-2$ & 0.125 & 1 \\
\hline imipenem & 100 & 0.0 & 0.0 & $\leq 0.006-4$ & 0.125 & 0.5 \\
\hline metronidazole & 71.4 & 19.0 & 9.5 & $\leq 0.006-64$ & 0.125 & 4 \\
\hline \multicolumn{7}{|l|}{ Bacteroides sp. (11) } \\
\hline amoxicillin & 81.8 & 0.0 & 18.2 & $\leq 0.006-128$ & 0.25 & 128 \\
\hline amoxicillin/clavulanate & 100 & 0.0 & 0.0 & $\leq 0.006-1$ & 0.25 & 1 \\
\hline benzylpenicillin & 81.8 & 0.0 & 18.2 & $\leq 0.006-256$ & 0.25 & 256 \\
\hline cefoxitin & 81.8 & 0.0 & 18.2 & $\leq 0.006-32$ & 0.125 & 32 \\
\hline imipenem & 100 & 0.0 & 0.0 & $\leq 0.006-4$ & 0.125 & 4 \\
\hline metronidazole & 100 & 0.0 & 0.0 & $\leq 0.006-2$ & 0.125 & 2 \\
\hline \multicolumn{7}{|l|}{ Eubacterium spp. (16) } \\
\hline amoxicillin & 100 & 0.0 & 0.0 & $\leq 0.006-0.25$ & $\leq 0.006$ & 0.25 \\
\hline amoxicillin/clavulanate & 100 & 0.0 & 0.0 & $\leq 0.006-0.25$ & $\leq 0.006$ & 0.25 \\
\hline benzylpenicillin & 100 & 0.0 & 0.0 & $\leq 0.006-0.5$ & $\leq 0.006$ & 0.5 \\
\hline cefoxitin & 100 & 0.0 & 0.0 & $\leq 0.006-0.5$ & $\leq 0.006$ & 0.5 \\
\hline imipenem & 100 & 0.0 & 0.0 & $\leq 0.006-0.5$ & $\leq 0.006$ & 0.125 \\
\hline metronidazole & 100 & 0.0 & 0.0 & $\leq 0.006-1$ & $\leq 0.006$ & 1 \\
\hline \multicolumn{7}{|l|}{ Fusobacterium spp. (42) } \\
\hline amoxicillin & 73.8 & 9.5 & 16.7 & $\leq 0.006-256$ & 0.125 & 32 \\
\hline amoxicillin/clavulanate & 100 & 0.0 & 0.0 & $\leq 0.006-0.5$ & $\leq 0.006$ & 0.5 \\
\hline benzylpenicillin & 71.4 & 11.9 & 16.7 & $\leq 0.006-256$ & 0.125 & 32 \\
\hline cefoxitin & 97.6 & 2.4 & 0.0 & $\leq 0.006-8$ & $\leq 0.006$ & 8 \\
\hline imipenem & 100 & 0.0 & 0.0 & $\leq 0.006-0.5$ & $\leq 0.006$ & 0.5 \\
\hline metronidazole & 100 & 0.0 & 0.0 & $\leq 0.006-0.5$ & $\leq 0.006$ & 0.25 \\
\hline \multicolumn{7}{|l|}{${ }^{1}$ Peptostreptococcus spp. (25) } \\
\hline amoxicillin & 92 & 8 & 0.0 & $\leq 0.006-16$ & $\leq 0.006$ & 0.5 \\
\hline amoxicillin/clavulanate & 100 & 0.0 & 0.0 & $\leq 0.006-0.5$ & $\leq 0.006$ & 0.5 \\
\hline benzylpenicillin & 88 & 8 & 4 & $\leq 0.006-16$ & $\leq 0.006$ & 0.5 \\
\hline cefoxitin & 100 & 0.0 & 0.0 & $\leq 0.006-2$ & $\leq 0.006$ & 1 \\
\hline imipenem & 100 & 0.0 & 0.0 & $\leq 0.006-0.5$ & $\leq 0.006$ & 0.5 \\
\hline metronidazole & 92 & 8 & 0.0 & $\leq 0.006-16$ & 0.125 & 1 \\
\hline \multicolumn{7}{|l|}{ Porphyromonas spp. (33) } \\
\hline amoxicillin & 100 & 0.0 & 0.0 & $\leq 0.006-0.25$ & $\leq 0.006$ & 0.25 \\
\hline amoxicillin/clavulanate & 100 & 0.0 & 0.0 & $\leq 0.006-0.25$ & $\leq 0.006$ & 0.25 \\
\hline benzylpenicillin & 100 & 0.0 & 0.0 & $\leq 0.006-0.5$ & $\leq 0.006$ & 0.5 \\
\hline cefoxitin & 100 & 0.0 & 0.0 & $\leq 0.006-0.5$ & $\leq 0.006$ & 0.5 \\
\hline imipenem & 100 & 0.0 & 0.0 & $\leq 0.006-0.25$ & $\leq 0.006$ & 0.25 \\
\hline metronidazole & 100 & 0.0 & 0.0 & $\leq 0.006-0.25$ & $\leq 0.006$ & 0.25 \\
\hline \multicolumn{7}{|l|}{ Prevotella spp. (28) } \\
\hline amoxicillin & 71.4 & 14.3 & 14.3 & $\leq 0.006-256$ & 0.25 & 128 \\
\hline amoxicillin/clavulanate & 96.4 & 3.6 & 0.0 & $\leq 0.006-8$ & 0.125 & 2 \\
\hline benzylpenicillin & 67.9 & 17.9 & 14.3 & $\leq 0.006-512$ & 0.25 & 128 \\
\hline cefoxitin & 78.6 & 7.1 & 14.3 & $\leq 0.006-128$ & 0.5 & 64 \\
\hline imipenem & 100 & 0.0 & 0.0 & $\leq 0.006-1$ & $\leq 0.006$ & 1 \\
\hline metronidazole & 100 & 0.0 & 0.0 & $\leq 0.006-0.5$ & $\leq 0.006$ & 0.5 \\
\hline \multicolumn{7}{|l|}{ Veillonella sp. (11) } \\
\hline amoxicillin & 100 & 0.0 & 0.0 & $\leq 0.006-2$ & 0.25 & 1 \\
\hline amoxicillin/clavulanate & 100 & 0.0 & 0.0 & $\leq 0.006-0.25$ & $\leq 0.006$ & 0.25 \\
\hline benzylpenicillin & 100 & 0.0 & 0.0 & $\leq 0.006-2$ & 0.25 & 1 \\
\hline cefoxitin & 100 & 0.0 & 0.0 & $\leq 0.006-0.5$ & $\leq 0.006$ & 0.5 \\
\hline imipenem & 100 & 0.0 & 0.0 & $\leq 0.006-0.25$ & $\leq 0.006$ & 0.25 \\
\hline metronidazole & 100 & 0.0 & 0.0 & $\leq 0.006-0.25$ & $\leq 0.006$ & 0.25 \\
\hline
\end{tabular}


Table II. Production of ß-lactamases by oral microorganisms isolated from chronic or aggressive periodontitis.

$\begin{array}{lc}\text { *Taxon (N) } & \begin{array}{c}\text { Production of } \beta \text {-lactamases } \\ \mathbf{N}(\%)\end{array} \\ \text { Bacteroides sp. (2) } & 0(0.0) \\ \text { Fusobacterium spp. (12) } & 12(100) \\ \text { Peptostreptococcus spp. (2) } & 0(0.0) \\ \text { Prevotella spp. (9) } & 8(88.9) \\ \text { Total (25) } & 20(80)\end{array}$

*Isolates presenting resistance or intermediate susceptibility to the tested $b$ lactams.

results of Table II suggest that ß-lactamases from anaerobic Gram-negative bacteria are active on penicillins and cephalosporins, as also described by Wybo et al. (2007) and Gaetti-Jardim Júnior et al. (2007).

The association of amoxicillin/clavulanate and imipenem were the most effective b-lactams against all tested isolates, including amoxicillin, penicillin $\mathrm{G}$ and metronidazole resistant microorganisms. This effectiveness is related to the action of clavulanate in inhibiting most $ß$-lactamases of oral microorganisms (Gaetti-Jardim Júnior et al., 2007) and the stability of carbapenems against most frequent $ß$-lactamases. Although imipenem-hydrolyzing class $D$ ß-lactamase has been identified, the present investigation evidenced that all blactamase producers were highly susceptible to this carbapenem. However, due to its effectiveness on pseudomonads and other resistant microorganisms, the use of carbapenems should be restrict to severe infections, particularly life-threatening diseases, to avoid dissemination of resistance (Gaetti-Jardim Júnior et al., 2007).

In the present investigation, some isolates that are resistant to b-lactams were not to be producers of ß-lactamase by the methodology employed in this study (Table II), suggesting suggests that these microorganisms are producers of non-exportable ß-lactamases, as previously reported in Gram-negative bacteria (Handal et al., 2004; Gaetti-Jardim Júnior et al., 2007).

\section{CONCLUSION}

The results of this study evidenced that resistance to ß-lactams among microorganisms isolated from aggressive and chronic periodontitis is limited to a few genera of strict obligate anaerobes, which were highly susceptible to metronidazole. Imipenem and the association of amoxicillin and clavulanate may overcome the problem of resistance to ß-lactams. The resistance to metronidazole was restricted to some isolates of A. actinomycetemcomitans, a facultative rod.
GAETTI-JARDIM JÚNIOR, E. \& SCHWEITZER, C. M. Susceptibilidad antimicrobiana a ß-lactámicos y metronidazol de microorganismos aislados de periodontitis crónica y agresiva. Int. J. Odontostomat., 7(2):193-198, 2013.

RESUMEN: El objetivo fue evaluar la susceptibilidad a ß-lactámicos y metronidazol, y evaluar la producción de ß-lactamasas por microorganismos aislados de pacientes con periodontitis crónica y agresivo. Las muestras fueron obtenido de 50 pacientes con periodontitis y microorganismos aislados en medios de cultivo selectivos y no selectivos, identificados por métodos bioquímicos y probados a la susceptibilidad a los antimicrobianos (amoxicilina, amoxicilina/clavulanato, cefoxitina, imipenem, metronidazol, penicilina G). Los aislados fueron resistentes a por lo menos $1 \mathrm{mg} / \mathrm{ml}$ de cualquier drogas analizadas fueron evaluados para verificar la producción de ß-lactamasas por el método de doble capa (o biológico) y nitrocefina. Los resultados mostraron resistencia a amoxicilina y penicilina $\mathrm{G}$, mientras la susceptibilidad a la asociación amoxicilina/ clavulanate, cefoxitina y imipenem fue ampliamente difundido entre los microrganismos. Resistencia a estas drogas mostraron una clara correlación con la producción de ß-lactamasas en la mayoría de grupos microbianos.

PALABRAS CLAVE: periodontitis, antimicrobianos, ß-lactámicos, bacteria, metronidazol.

\section{REFERENCES}

Ahuja, A.; Baiju, C. S. \& Ahuja, V. Role of antibiotics in generalized aggressive periodontitis: a review of clinical trials in humans. J. Indian Soc. Periodontol.; 16(3):317-23, 2012.

Baumgartner, J. C. \& Xia, T. Antibiotic susceptibility of bacteria associated with endodontic abscesses. J. Endod., 29(1):44-7, 2003.

Brescó-Salinas, M.; Costa-Riu, N.; Berini-Aytés, L. \& Gay-Escoda, C. Antibiotic susceptibility of the bacteria causing odontogenic infections. Med. Oral Patol. Oral Cir. Bucal., 11(1):70-5, 2006.

Casarin, R. C. V.; Peloso Ribeiro, E. D.; Sallum, E. A.; Nociti, F. H. Jr.; Goncalves, R. B. \& Casati, M. $Z$. The combination of amoxicillin and metronidazole improves clinical and microbiologic results of one-stage, full-mouth, ultrasonic debridement in aggressive periodontitis treatment. J. Periodontol., 83(8):988-98, 2012. 
GAETTI-JARDIM JÚNIOR, E. \& SCHWEITZER, C. M. Antimicrobial susceptibility to b-lactams and metronidazole of microorganisms isolated from chronic and aggressive periodontitis. Int. J. Odontostomat., 7(2):193-198, 2013.

Clinical and Laboratory Standards Institute. Methods for antimicrobial susceptibility testing of anaerobic bacteria: approved standard, CLSI document M11-A7. Wayne, PA, Clinical and Laboratory Standards Institute, 2007.

Eick, S.; Straube, A.; Guentsch, A.; Pfister, W. \& Jentsch, H. Comparison of real-time polymerase chain reaction and DNA-strip technology in microbiological evaluation of periodontitis treatment. Diagn. Microbiol. Infect. Dis.; 69(1):12-20, 2011.

Fosse, T.; Madinier, I.; Hannoun, L; Giraud-Morin, C.; Hitzig, C.; Charbit, Y. \& Ourang, S. High prevalence of cfXA ßlactamase in aminopenicillin-resistant Prevotella strains isolated from periodontal pockets. Oral Microbiol. Immunol., 17(2):85-8, 2002.

Gaetti-Jardim Júnior, E.; Landucci, L. F.; Lins, S. A.; Vieira, E. M. \& de Oliveira, S. R. Susceptibility of strict and facultative anaerobes isolated from endodontic infections to metronidazole and ß-lactams. J. Appl. Oral Sci., 15(6):539-45, 2007.

Gaetti-Jardim, E. Jr.; Monti, L. M.; Ciesielski, F. I. N.; GaettiJardim, E. C.; Okamoto, A. C.; Schweitzer, C. M.; et al. Subgingival microbiota from Cebus apella (capuchin monkey) with different periodontal conditions. Anaerobe, 18(3):263-9, 2012.

Handal, T.; Olsen, I.; Walker, C. B. \& Caugant, D. A. blactamase production and antimicrobial susceptibility of subgingival bacteria from refractory periodontitis. Oral Microbiol. Immunol., 19(5):303-8, 2004.

Kuriyama, T.; Karasawa, T.; Nakagawa, K.; Nakamura, S. \& Yamamoto, E. Antimicrobial susceptibility of major pathogens of orofacial odontogenic infections to 11 ßlactam antibiotics. Oral Microbiol. Immunol., 17(5):2859, 2002.

López, R.; Dahlén, G.; Retamales, C. \& Baelum, V. Clustering of subgingival microbial species in adolescents with periodontitis. Eur. J. Oral Sci., 119(2):141-50, 2011.

Senhorinho, G. N.; Nakano, V.; Liu, C.; Song, Y.; Finegold, S. \& Avila-Campos, M. J. Occurrence and antimicrobial susceptibility of Porphyromonas spp. and Fusobacterium spp. in dogs with and without periodontitis. Anaerobe, 18(4):381-5, 2012.

Wybo, I.; Piérard, D.; Verschraegen, I.; Reynders, M.; Vandoorslaer, K.; Claeys, G.; et al. Third Belgian multicentre survey of antibiotic susceptibility of anaerobic bacteria. J. Antimicrob. Chemother., 59(1):132-9, 2007.
Correspondence to:

Elerson Gaetti Jardim Junior

Department of Pathology and Clinical Propaedeutics

Rua José Bonifácio, 1193

Vila Mendonça, 16015-050

Araçatuba, São Paulo

BRASIL

Tel.: +55-18-3636-2797

Fax: +55-18-3636-3224

Email: egaettij@foa.unesp.br

Received: 07-11-2012

Accepted: 22-03-2013 